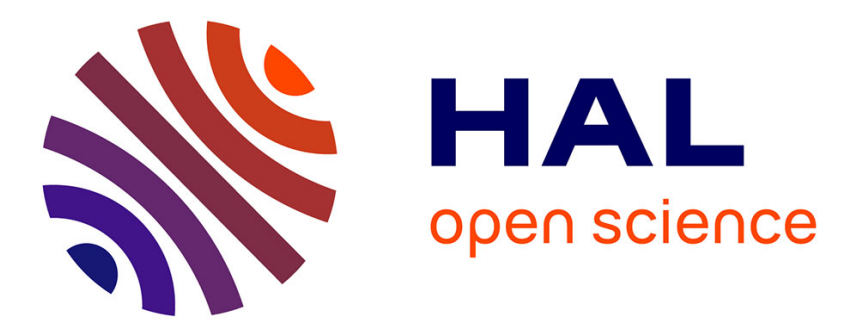

\title{
FE modelling of bainitic steels using crystal plasticity
}

Nikolay Osipov, Anne-Françoise Gourgues-Lorenzon, Bernard Marini, Valérie Mounoury, Franck N'Guyen, Georges Cailletaud

\section{To cite this version:}

Nikolay Osipov, Anne-Françoise Gourgues-Lorenzon, Bernard Marini, Valérie Mounoury, Franck N'Guyen, et al.. FE modelling of bainitic steels using crystal plasticity. Philosophical Magazine, 2009, 88 (30-32), pp.3757-3777. 10.1080/14786430802566380 . hal-00513993

\section{HAL Id: hal-00513993 \\ https://hal.science/hal-00513993}

Submitted on 1 Sep 2010

HAL is a multi-disciplinary open access archive for the deposit and dissemination of scientific research documents, whether they are published or not. The documents may come from teaching and research institutions in France or abroad, or from public or private research centers.
L'archive ouverte pluridisciplinaire HAL, est destinée au dépôt et à la diffusion de documents scientifiques de niveau recherche, publiés ou non, émanant des établissements d'enseignement et de recherche français ou étrangers, des laboratoires publics ou privés. 


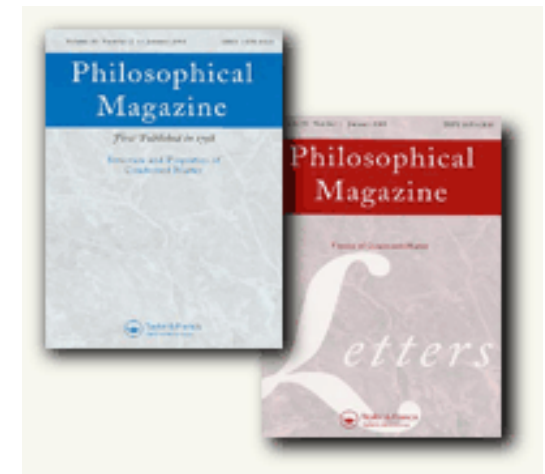

FE modelling of bainitic steels using crystal plasticity

\begin{tabular}{|r|l|}
\hline Journal: & Philosophical Magazine \& Philosophical Magazine Letters \\
\hline Manuscript ID: & TPHM-08-Jan-0030.R3 \\
\hline Journal Selection: & Philosophical Magazine \\
\hline Author: & $17-$ Oct-2008 \\
\hline Complete List of Authors: & $\begin{array}{l}\text { Osipov, Nikolay; Ecole des Mines de Paris, Centre des Matériaux; } \\
\text { Ecole des Mines de Paris, Centre des Matériaux } \\
\text { Gourgues-Lorenzon, Anne-Françoise; Ecole des Mines de Paris, } \\
\text { Centre des Matériaux, CNRS UMR 7633 } \\
\text { Marini, Bernard; CEA, SRMA } \\
\text { Mounoury, Valérie; Ecole des Mines de Paris, Centre des Matériaux, } \\
\text { CNRS UMR 7633 } \\
\text { N'Guyen, Franck; Ecole des Mines de Paris, Centre des Matériaux, } \\
\text { CNRS UMR 7633 } \\
\text { Cailletaud, Georges; Ecole des Mines de Paris, Centre des } \\
\text { Matériaux, CNRS UMR 7633 }\end{array}$ \\
\hline Keywords: & $\begin{array}{l}\text { bainitic transformation, crystals, finite-element modelling, grain } \\
\text { boundaries, stainless steels }\end{array}$ \\
\hline Keywords (user supplied): & voronoi tessellation \\
\hline \hline
\end{tabular}

\section{s scholaroNE" \\ Manuscript Central}


${ }^{*}$ Corresponding author. Email: Nikolay.Osipov@ensmp.fr

\section{Philosophical Magazine}

Models classically used to describe the probability of brittle fracture in nuclear power plants are written on a macroscale. Physical phenomena are not naturally captured by this type of approach, so that application of these models far from their identification domain (such as temperature history, loading path) may become questionable. To improve the quality of the prediction of resistance and life time, microstructural information describing the heterogeneous character of the material and its deformation mechanisms, has to be taken into consideration. The objectives of this work is to propose a model able to describe local stress and strain fields in an A508 $\mathrm{Cl} 3$ bainitic steel. This information will then be used to introduce critical variables for multiscale failure models. The microstructure of A508 Cl3 steel is made of bainitic packets (coming from former austenitic grains), which are not randomly oriented. An accurate model must take the actual microstructure into account, in order to provide realistic local stress and strain fields. Starting from experimental observations of the bainitic microstructure (texture measurements, morphological analysis), the paper first proposes a numerical model able to produce quantitatively representative numerical aggregates, then discusses the results obtained by a finite element treatment of the aggregates involving crystal plasticity.

\section{Introduction}

Reactor pressure vessel steel of nuclear power plant (A508 Cl3, 16MND5 in French norm) type shows a soft but well defined temperature dependence of the toughness in the range of the Ductile to Brittle Transition Temperature (DBTT) [1-7]. In practice, toughness data and its scattering can be accurately described in the whole transition, thanks to fracture modelling, based on local approach models such as Beremin or WST models [2,3]. However, to reproduce the fast increase of toughness with temperature in the DBTT region, the macroscopic critical cleavage stress must be assumed to be an increasing function of temperature [4-7]. On one hand, in pure Fe, experiments reveal that the surface energy $\gamma_{s}$ which is related to the cleavage stress, is fairly independent of temperature $[8,9]$. On the other hand, for bainitic steels, it is experimentally found that the macroscopic critical cleavage stress is fairly temperature independent, at least, in the lower shelf of the fracture toughness [10]. Therefore, introduction of a temperature-dependent macroscopic critical cleavage stress in computations needs to be rationalised. The reasons of this effect can be investigated by means of a multi-scale approach, starting from dislocation behaviour and going through different scales $[11,12]$. Crystal plasticity is a good candidate to be the lower level of the scheme, since it describes the collective behaviour of dislocations and allows to evaluate local stress fields in connection with the material microstructure. The critical variables controlling brittle fracture (namely, the largest eigenstress value) can be found from these fields. Of course, this requires precise computation of the local stress distributions within the aggregate, that can only be achieved if a representative model of the microstructure (texture and grain morphology) is used.

Calculation of microstructures is now a classical field in computational material mechanics [13]. In early studies, only the global response was investigated, together with texture evolution, so that cubic grains where used, with one element in each grain $[14,15]$. Authors have then introduced regular grain shapes with many finite elements in each grain [16], then the so-called multiphase elements [17, 18], in 
order to better characterise intergranular fields. The values obtained near grain boundaries with this technique are questionable, so that more advanced solutions, using realistic meshes obtained by a Voronoï tessellation $[18,19]$ or other algorithms [20] have been proposed, where the finite element mesh conforms grain boundaries.

Meshing techniques can be applied either on synthetic images, or on real pictures of the material. The second solution is the most classical for $2 \mathrm{D}$ microstructures [21]. It has also been used also in 3D computations, where the 3D image is obtained by successive polishing operations or by X-ray tomography [7,19]. For the present case, it might not be the best one, since the chance to choose a non representative window remains significant on very complex microstructures. On the other hand, better control is allowed by numerical image generation, because the number of microstructure maps is not limited, so that the statistical aspect is easier to introduce.

Metallurgists have characterised the bainitic microstructures for a long time [22-25]. These steels are formed of grains and subgrains (bainitic packets), that have well defined orientations with respect to the initial austenitic grain. If compared to a simple aggregate computation, the present problem must then introduce two new features: a fully controlled local texture (not only average texture components, but spatially related crystal orientations) and grains (in fact packets) defined by a two level procedure, where the shape of the packets is defined inside an initial domain. From the best authors' knowledge, the consequences of these choices have not been addressed together in literature.

Variables characterising the hydrostatic and the deviatoric stress, or more likely the maximum eigenstress are to be used in the micromechanical local approach. Their respective maps will be studied in detail in a future paper. For the present article, we focus on the von Mises equivalent stress, since the related distributions exhibit profiles that were not shown before in literature.

The purpose of the paper is then first to propose a new methodology to produce spatially controlled microstructures, then to check the consequences of their specific properties on the local stress fields obtained by a finite element analysis. After the present introduction, the paper is divided into six sections. Section 2 summarises several preexisting useful observations of the microstructure of the material in order to present the retained morphology. Section 3 provides detailed analysis of the various scales and proposes a simplified morphology; several solutions are investigated to create bainitic packets by cutting a parent austenitic grain into several daughter packets. The chosen cutting process is then used to model the whole aggregate, which is shown in Section 4, as the result of the morphological and textural modelling strategy. The target morphology and textures are given. Section 5 provides a description of the material model, and boundary conditions, and presents FE computations. Two series of results are then presented. The main part is Section 6, were the influence of the crystallography and of the morphology on the local and global stress-strain responses are shown. Section 7 is devoted to a discussion dealing with mesh types and the possible artefacts that can arise from a loose mapping of the microstructure on the FE mesh.

\section{Observation and morphological analysis of bainitic microstructures}

\subsection{Process dependent microstructures}

The material under study is a A508 Cl3 bainitic steel used in Pressurised Water Reactors (PWR) pressure vessels. Its chemical composition is given in Table 1.

\begin{tabular}{ccccccccccc}
\hline $\mathrm{C}$ & $\mathrm{S}$ & $\mathrm{P}$ & $\mathrm{Si}$ & $\mathrm{Mn}$ & $\mathrm{Ni}$ & $\mathrm{Cr}$ & $\mathrm{Mo}$ & $\mathrm{Cu}$ & $\mathrm{Co}$ & $\mathrm{V}$ \\
0.16 & 0.004 & 0.008 & 0.22 & 1.33 & 0.76 & 0.22 & 0.51 & 0.07 & 0.017 & $\leq 0.01$ \\
\hline
\end{tabular}

Table 1. Chemical analysis (wt \%) of the steel under study

Advanced experimental techniques (image analysis, EBSD) reveal a very complex microstructure, that results from several heat treatments, which aim to suppress forging effects, reduce residual stresses in the material and define the final morphology and relevant crystal orientations. Three steps are successively applied: (i) austenitisation at $865^{\circ} \mathrm{C}$ and $895^{\circ} \mathrm{C}$ during $4 \mathrm{~h} 40$. An homogeneous microstructure composed of equiaxed austenitic (FCC) grains is formed (Fig. 1(a)); (ii) water quenching. The crystallographic structure 


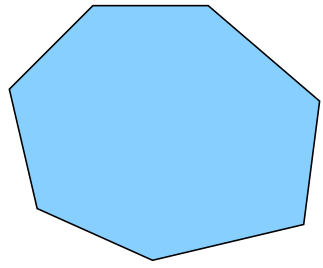

(a)

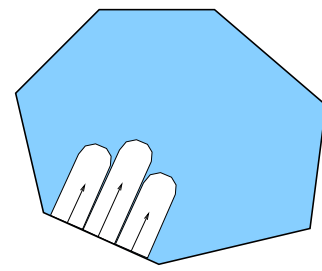

(b)

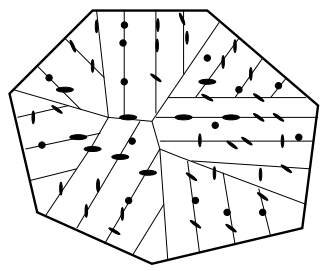

(c)

Figure 1. Principal stages of the austenite-bainite phase transformation
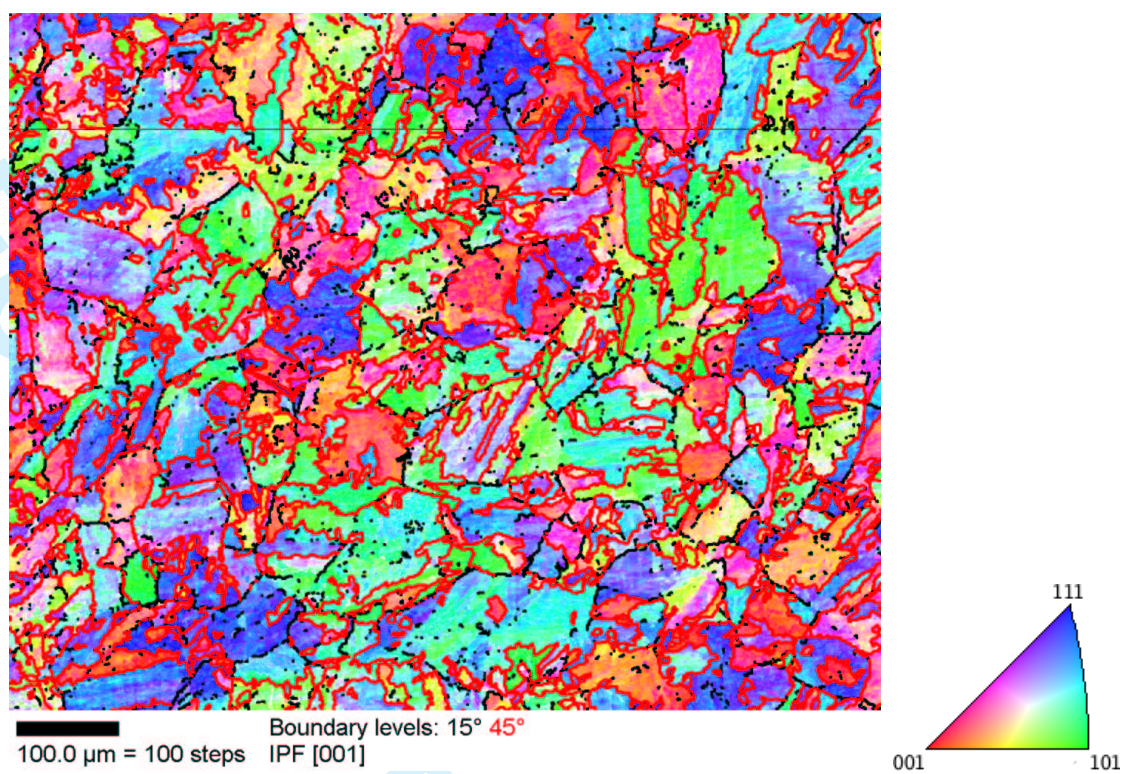

Figure 2. Inverse Pole Figure map of a A508 Cl3 microstructure (doc. CEA). The color key indicates the orientation of the sample normal in each crystal frame

transforms from FCC into BCC. The ferritic phase starts to grow from nucleation sites generally located at grain boundaries or multiple junctions (Fig. 1(b)); (iii) tempering at $630^{\circ} \mathrm{C} / 645^{\circ} \mathrm{C}$ during $7 \mathrm{~h} 30$ and stressrelief heat treatment at $610^{\circ} \mathrm{C}$ during 8 hours. Cementite is then formed, due to carbon precipitation at grain and subgrain boundaries. This mixture of ferrite and cementite will be called bainite in the following (Fig. 1(c)).

\section{$2.2 \quad$ Analysis of morphology and crystallography of bainitic steel}

Inclusions such as $\mathrm{MnS}$ as well as a low amount of remaining austenite are found in the material. Such a complex microstructure is known to have an influence on the failure mode: brittle failure is the consequence of cleavage mechanisms along cubic planes of the BCC phase. The Electron Back Scattered Diffraction (EBSD) technique is one of the most advanced methods used to characterise the internal microstructure of the grains. This method has been used to obtain the Inverse Pole Figure (IPF) map of a typical microstructure of our steel as presented in Figure 2. It shows that the material has a complex tempered bainite microstructure: it consists of groups of ferritic laths (contoured by red lines) which present slight relative misorientations (about 1-2 degrees). This groups are also called sheaves [26] or packets. The packets with a distinct crystallographic orientation (i.e. delimited by a high angle boundary) define the effective grain size of the material with respect to cleavage. Further, the image analysis was performed using OIM Analysis software. It revealed morphological characteristics (size and shape of grains) and crystallographic information (IPF, misorientation angle) of the material.

The obtained crystallographic information is graphically presented in Fig.3. It should be noted that in our analysis we considered that the specific processing route does not create any texture in austenite. Thus, it does not affect the misorientation of packets across former austenite grain boundaries. Figure 


\section{Modelling of the bainitic microstructure}

\subsection{Morphology of the bainitic phase}

Bainite is the result of a phase transformation starting from an austenitic microstructure. A correct modelling of the parent microstructure (former austenite) is then a key point in the procedure used to generate the final (product) microstructure. For this purpose, classical Voronoï tessellation was used. A repulsion function allows to control grain shape and grain size distribution. It is worth noting that EBSD maps give information from a surface of a $3 D$ microstructure, consequently only a $3 D$ numerical microstructure can be used for its modelling. Due to to the complexity of the microstructure, cleavage properties are related to local matrix microtexture (i.e. combined morphology and crystallography) and to secondary phase distribution. Only matrix properties will be considered in the following of this paper.

The main goal of this work is a correct representation of the bainitic microstructure, taking into account the morphology and crystallography of bainitic packets, in order to estimate the heterogeneity of stress and strain fields induced by this intragranular microstructure and understand its origin. That is the reason why only bainitic packets are considered. The influence of secondary phases such as cementite has been deeply studied in a previous study [27], where clusters of cementite have been taken into account by means of a two phase model. In the present work, the precipitation of cementite is taken into account implicitly in the material parameters of the constitutive model. The definition of the shape of the bainitic packets is still controversial. EBSD analysis allows researchers to better understand the morphology and the crystallography of the microstructure (Fig. 2). Starting from experimental EBSD data (Fig. 2), several cutting processes were defined to generate the bainitic packets. Five cutting methods are presented here. They are illustrated in Fig. 4. As shown in Fig. 4(a), type I consists in the definition of a given number of packets as parallel slices of the parent grain which are cut along given direction. In type II, a volume ${ }^{1}$ decomposition (Fig. 4(b)) allows various sub-domains to be considered. Type III (Fig. 4(c)) is a combination of the first and second types of cutting which changes from one grain to another in a random manner. Analysis of partially transformed bainite samples suggests that bainitic packets frequently originate from the parent grain boundaries. This idea is used in the type $I V$ rule (Fig. 4(d)), where grains are decomposed

${ }^{1}$ The numerical methods of grain to packet decomposition are developed in $3 D$, even if, for the sake of simplicity, only $2 D$ images are presented. 


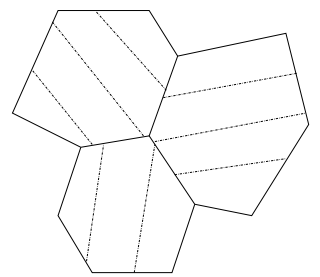

(a) Type I

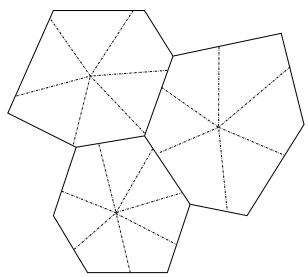

(b) Type II

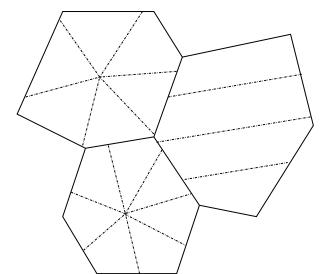

(c) Type III

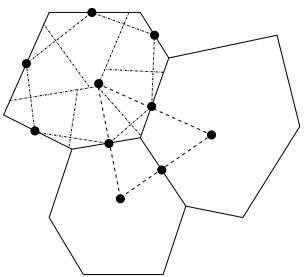

(d) Type IV

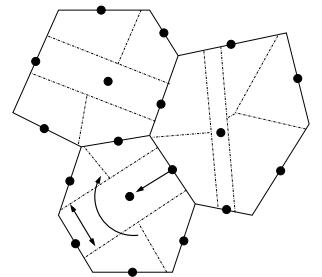

(e) Type V

Figure 4. Graphical illustration of the various cutting rules adopted in this study

into packets using a Voronoï tessellation with the subgrains nuclei located at the grain boundary in the middle between centers of two contiguous grains. However, as the size of cleavage facets is close to the parent austenite grain size, it can be suggested that at least one packet per austenite grain is able to grow freely from one grain boundary to another. This was simulated by type $V$ cutting rule (Fig. 4(e)). After selection of one particular variant, which will expand freely throughout the grain, other variants can start to grow from nuclei located in the middle of the remaining grain boundary with equal rates, so that they will fill the volume of the parent grain and divide it into packets following a Voronoï tessellation.

\section{$3.2 \quad$ Texture analysis}

Since the material was submitted to several austenising heat treatments, we consider that all the traces of the initial forming process have vanished and that no texture remains in the initial austenitic phase.

The relative orientations of the bainitic packets and the parent austenite are defined by classical theories, such as Kurdjumov-Sachs(KS) or Nishiyama-Wassermann(NW) [28-30] relationships. In bainitic steels, it is usually observed that crystal orientations always lie within the Bain region, which encompasses the KS and NW relationships, while never being exactly KS or NW [26]. The respective orientation relationships are:

$$
\begin{array}{ccccc}
\operatorname{KS}(111) \gamma & / / & (011) \alpha \text { and }[\overline{1} 10] \gamma & / / & {[\overline{1} \overline{1} 1] \alpha} \\
\operatorname{NW~}(111) \gamma & / / & (011) \alpha \text { and }[\overline{1} 2 \overline{1}] \gamma & / / & {[\overline{0} \overline{1} 1] \alpha}
\end{array}
$$

These orientation relationships only differ by a relative rotation of $5.25^{\circ}$ about the normal to the parallel close-packed planes of the two structures. The KS relationships lead to 24 possible variants while 12 variants are predicted by the NW relationships. This leads to a large number of possible orientation relationships between all these variants.

In order to quantify possible misorientations between the variants satisfying NW and KS relations, the following two tests have been done: it was supposed that all the former austenitic grains have the same crystallographic orientation (100). Orientations of bainitic packets were then calculated assuming that only NW relationships for the first test and only KS relationships for the second one were satisfied and all the variants were equiprobable. The resulting misorientations are shown in Fig. 5, which shows that there are only 5 possible misorientations between bainitic packets in the same grain if NW relationships are used. KS relationships give 12 possible misorientations. The discrete values resulting from the computations are shown using a impulse type diagram: it shows that each type of relationships create two misorientation families - in the 10-20 degrees range and in the 45-60 degrees range. The theoretical misorientations provided by the models are in good agreement with the experimental distribution previously shown in Fig. 3. In the following sections only the NW relationships will be used.

\section{Methodology of analysis of numerical microstructure}

\subsection{Description of the procedure}

In the present work, the question of microstructure generation is closely connected to the mesh generation problem. The current version of the microstructure generation tools uses different types of group definitions 


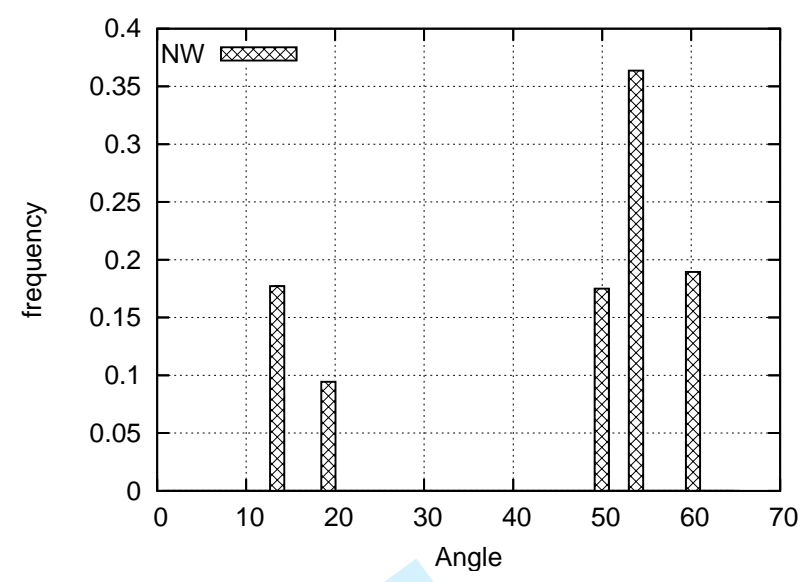

(a)

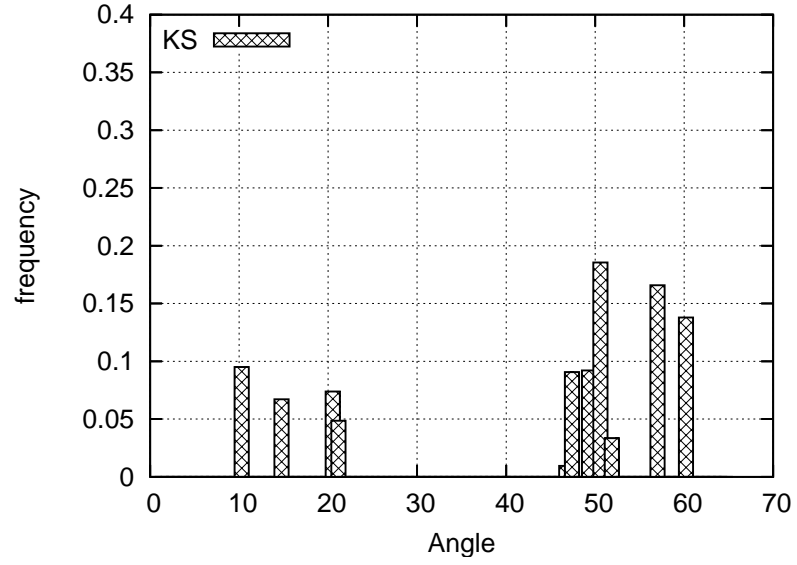

(b)

Figure 5. Theoretical misorientations of variants: (a) generated using NW relationships; (b) generated using KS relationships

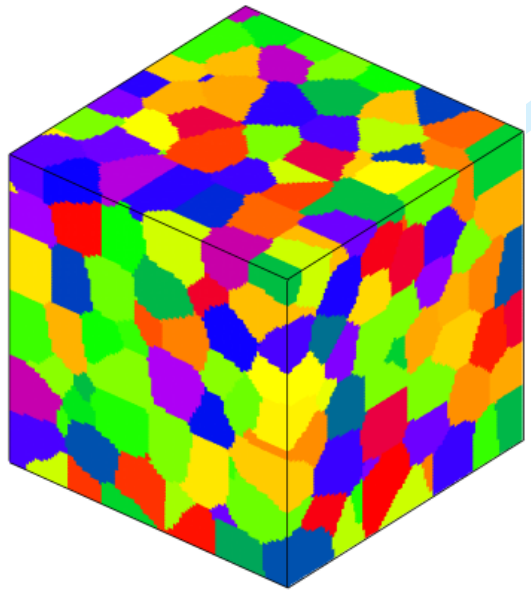

(a)

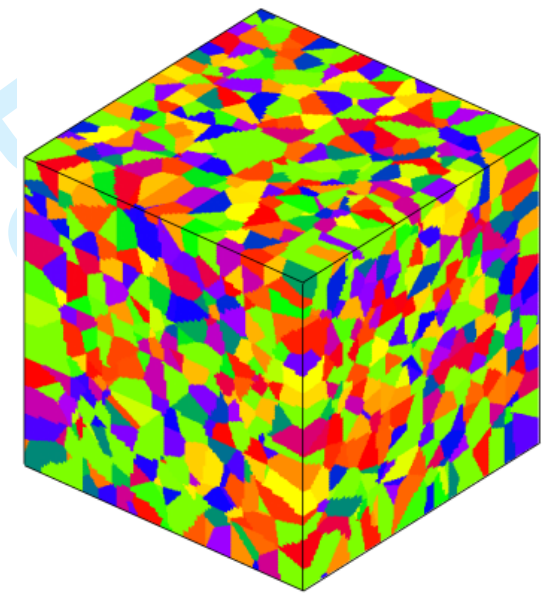

(b)

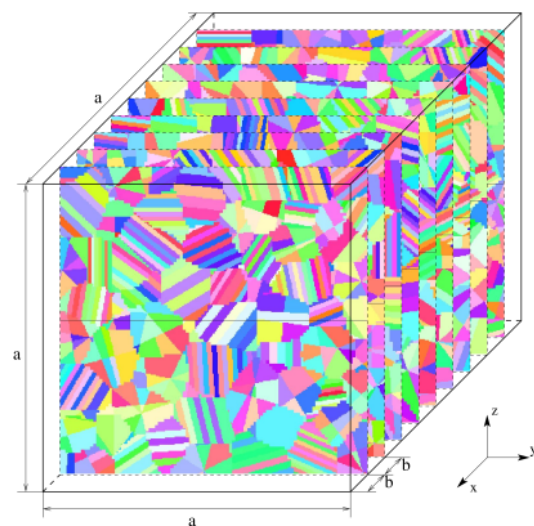

(c)

Figure 6. Type IV of cutting: (a) parent microstructure (400 grains); (b) resulting microstructure (4700 bainitic packets); (c) numerical EBSD maps. The same color key as in Fig. 2

to describe a granular structure: groups of integration points (IPSETs), groups of elements (ELSETs) and mixed methods (see [31] for more details). Both definition modes take the information from a 3D image, that is now defined on a cube decomposed into $300 \times 300 \times 300$ voxels. In order to avoid generation of microstructures composed of parallel slices only or without slices at all, types $I$ and $I I$ have not been used here. Thus only types type III, $I V$ and $V$ were tested. The procedure used for the analysis consists of various steps:

- for all cutting rules, the same parent microstructure, made of 400 grains, was used (Fig. 6 (a));

- after applying the cutting rule (Fig. 6 (b)), nine parallel cross-sections were defined within the obtained microstructure. They were used to perform the image processing. The chosen number of cross-sections is consistent with the number of grains in microstructure: having 400 grains in the aggregate, it allows to have completely different parent grains in each cross-section;

- knowing the locations of voxels in the volume as well as the crystallographic orientations assigned to each voxel, it becomes possible to generate EBSD compatible numerical maps (Fig. 6 (c)); Information is saved for each cross-section in a format which allows to process them directly with the Orientation Image Microscopy (OIM) analysis tools;

- for each cross-section, grain size, grain aspect ratio and misorientation distribution, were plotted and averaged over the nine cross-sections. The average was then compared to experimental data. 


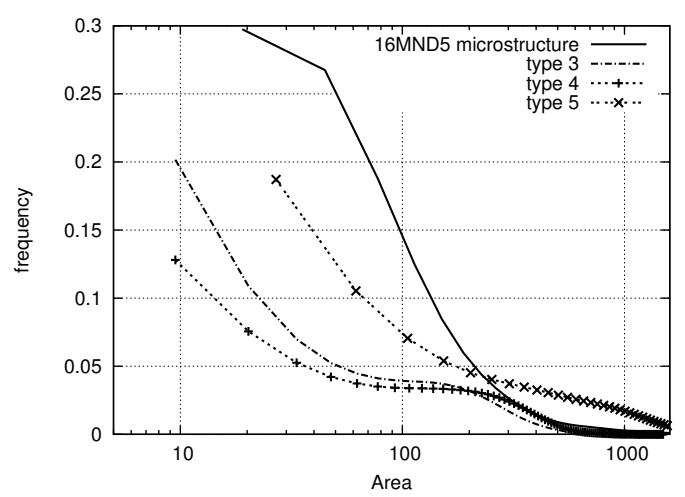

(a)

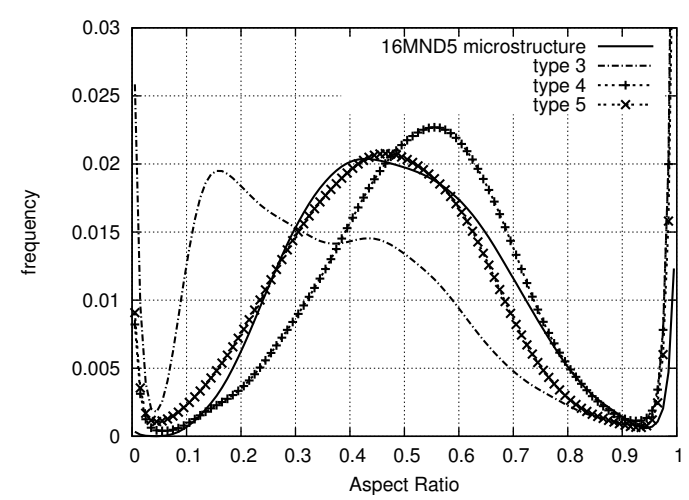

(b)

Figure 7. Comparison between A508 and numerical microstructures: (a) grain area; (b) aspect ratio distribution

\subsection{Morphological results}

A quantitative analysis of the average values of area and aspect ratio of the bainitic packets for different cutting rules has been made. The result is illustrated in Fig. 7, where the total population has been divided into 100 classes for each subfigure. It can be observed (Fig. 7 (a)) that the number of small grains is larger in experimental distribution than in any of the simulated microstructures. This is due to the use of a Voronoï tessellation algorithm which produces a rather uniform grain size. It has to be noted that the horizontal logarithmic scale magnifies this effect. This is why we decided to keep this kind of display. For the aspect ratio, the agreement is rather poor for Type III: this is related to the large number of slice-shaped grains in the microstructure. The maximum of the distribution is found for an aspect ratio of 0.15. Type IV fails also to reproduce the experiment, but now the maximum of the aspect ratio distribution is at 0.56 which is due to the rounded shape of subgrains. Finally, type $V$ allows to correctly describe the experimental grain shape distribution, since it introduces a special domain crossing each grain before cutting the rest of the grain: this appears to be an essential feature of the real microstructure, which remains absent in other cutting rules.

\subsection{Local texture}

The distribution of the misorientation angle between packets is shown in Fig. 8. NW assumptions are used, as previously shown in Fig. 5 (a). It is compared with the one, coming from the EBSD analysis of real microstructure shown in Fig. 2.

Again the population is divided into 100 classes for the case shown in Fig. 8 (b). The plot in Fig. 8 (a) is a little different, since, in this case, its would not be realistic to make a direct comparison of the numerical microstructure and of the experimental one. The simulated misorientations combine "ground" values coming from the misorientations of the former austenitic grains and the five discrete values coming from the NW relationships, represented by five Dirac functions. A scale factor of nine has then been applied to the experimental values on the vertical axis, to bring the corresponding continuous curve at the level of the simulated one.

In Fig. 8 (a) (dashed line), it can be seen that the experimental misorientation angle distribution presents a maximum between $50^{\circ}-60^{\circ}$, that is the maximum misorientation allowed for the cubic microstructure. Since theory provides a finite set of values, the experimental distribution was adjusted by the size of the classes used for counting. The qualitative agreement between experiment and theory is rather good. The angles in the range $0-15^{\circ}$ correspond to the misorientation between the laths of ferrite within the bainitic packets whereas the angles from $40^{\circ}$ to $62^{\circ}$ mainly correspond to the misorientation between the bainitic packets within the parent grains. Peaks on the curve corresponding to the numerical microstructure confirm the theoretical result: in a microstructure where only NW crystallographic relationships are present, only 5 possible misorientations between the bainitic packets can appear in the same grain. The background curve located between the peaks perfectly corresponds to the typical curve of misorientations of grains within a 


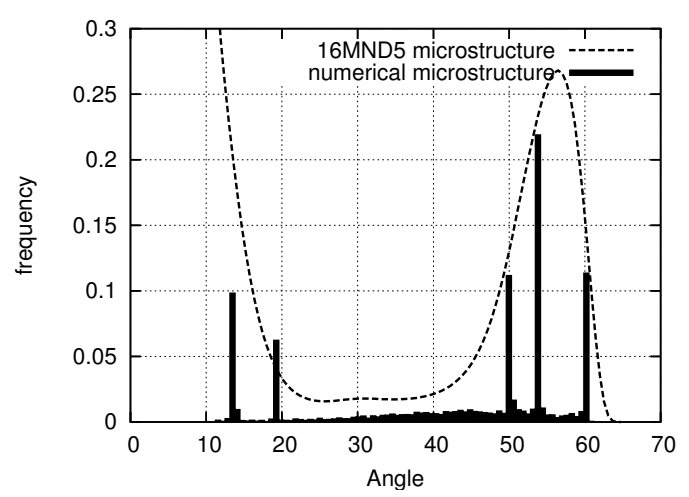

(a)

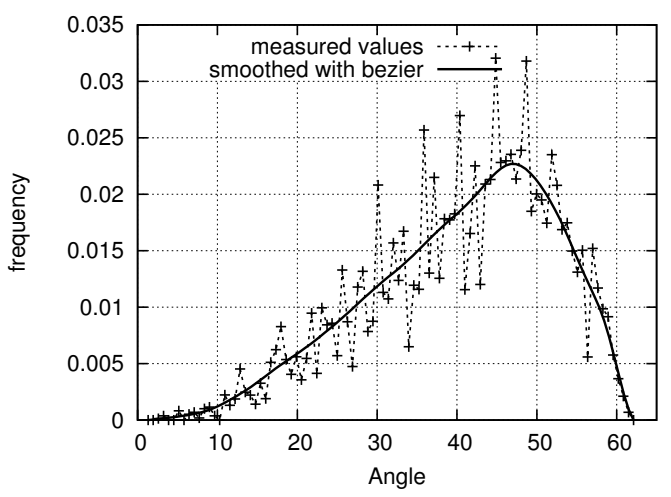

(b)

Figure 8. Comparison between A508 and numerical microstructures: (a) misorientation angle; (b) typical curve of misorientations of grains within a cubic lattice and random angle distribution between grains (McKenzie curve)

cubic lattice and random angle distribution between grains [34] (Fig. 8(b)).

\section{Modelling of the aggregate mechanical behavior}

\subsection{Mesh and boundary conditions}

Two strategies were used for generating meshes: the first one is called UM and involves an unstructured mesh generation $(\mathrm{U})$ of a parent austenitic microstructure followed by a mapping $(\mathrm{M})$ of the bainitic packets (using IPSETs (section 4)). Multiphase elements were then created. This mesh conforms parent grain boundaries but not packet boundaries within parent grains. The second method yields a full unstructured mesh (UU) (that is, unstructured for the initial austenitic microstructure (first U) and unstructured for the packets (second U)), so that the mesh conforms all boundaries. The first example to come (section 6 ) uses the UM technique, meanwhile the second one (section 7) introduces UU meshes.

The same mechanical problem was considered in all the computations presented in this paper. Mixed boundary conditions were applied, in order to simulate an uniaxial tensile test:

- the bottom face was fixed in the axial direction, and an axial displacement was prescribed on the top face, to reach $5 \%$ of strain;

- the four lateral faces were left free of charge;

- two points on the bottom face were fixed in order to avoid rigid body motion.

In all cases, quadratic elements were used, so that the precision of the computation is rather reasonable. Having in view the characterisation of critical variables in a RVE, it would be better to use periodic boundary conditions. This specific boundary condition is presently not compatible with the type of parallelism that is implemented in our FE code (sub-domain decomposition technique [35]). Nevertheless, the surface effect which is related to the presence of free surfaces in the FE model has been carefully analysed in the past $[18,37]$. It introduces more scatter in the result, and it decreases the hydrostatic pressure. It was observed in the present computations, that, due to the fine mesh, the stress redistribution can be quite rapid in the bulk of the material, and that, for instance, there is a non zero stress component perpendicular to the surface even in the first grain, for points lying just under the surface. As a consequence, it is assumed that the conditions of the computations do not prevent to obtain significant results.

\section{$5.2 \quad$ Material model}

The constitutive model used in this paper was introduced in [36]. It was extensively used for the computations of polycrystalline aggregates $[13,37]$. Thus, only the main equations are recalled below. The equations are written in a finite strain framework. For the sake of brevity, the terms corresponding to kinematic hardening are not displayed here. A classical multiplicative decomposition of the displacement 
gradient into elastic and viscoplastic part is used. The Lagrange type elasticity is introduced:

$$
\underset{\sim}{\mathbf{F}}=\underset{\sim}{\mathbf{F}^{e}}{\underset{\sim}{\mathbf{F}}}^{p} \quad ; \quad \underset{\sim}{\mathbf{E}^{e}}=\frac{1}{2}\left(\mathbf{F}_{\sim}^{\mathbf{e}^{T}} \underset{\sim}{\mathbf{F}^{e}}-\underset{\sim}{\mathbf{I}}\right) \quad ; \quad \underset{\sim}{\mathbf{S}}=\underset{\sim}{\mathbf{L}}: \underset{\sim}{\mathbf{E}^{e}}
$$

The local resolved shear stress is defined by means of a constant tensor $\mathbf{N}^{s 0}$, formed by means of the slip direction $\underline{1}^{s 0}$ and the normal to the slip plane $\underline{\mathbf{n}}^{s 0}$ :

$$
\tau^{\mathrm{s}}=\underset{\sim}{\boldsymbol{\Sigma}}:{\underset{\sim}{\mathbf{N}}}^{s 0} \quad ; \quad \underset{\sim}{\boldsymbol{\Sigma}}=J{\underset{\sim}{\mathbf{F}}}^{e} \underset{\sim}{\mathbf{F}^{e T}} \mathbf{S} \quad ; \quad \mathbb{\sim}^{s 0}=\underline{s}^{s 0} \otimes \underline{\mathbf{n}}^{s 0}
$$

Viscoplastic flow writes:

$$
{\underset{\sim}{\mathbf{L}}}^{p}={\underset{\sim}{\dot{\mathbf{F}}}}^{p} \mathbf{F}_{\sim}^{\mathbf{p}-1}=\sum_{s} \dot{\gamma}^{s} \mathbf{N}^{s 0}
$$

The viscoplastic shear strain rate for each slip system $s$ is:

$$
\dot{\gamma}^{\mathrm{s}}=\dot{v}^{\mathrm{s}} \operatorname{sign}\left(\tau^{\mathrm{s}}\right) \quad ; \quad \dot{v}^{\mathrm{s}}=\left\langle\frac{\left|\tau^{\mathrm{s}}\right|-r^{\mathrm{s}}}{K}\right\rangle^{n} \quad \text { with }\langle x\rangle=\operatorname{Max}(x, 0)
$$

An isotropic hardening rule is introduced on each slip system $s$. It involves an interaction matrix [h]:

$$
r^{\mathrm{s}}=R_{0}+Q \sum_{r} h_{s r}\left\{1-e^{-b v^{\mathrm{r}}}\right\}
$$

For each of the two slip families, a set of material parameters characterises the initial critical resolved shear stress $\left(R_{0}^{b c c 110}, R_{0}^{b c c 112}\right)$, hardening $(Q, b)$ and viscosity $(n, K)$. In the present study the area of interest does not exceed a few per cent of deformation, so that the computations were made with a small strain assumption.

\subsection{Calibration of the FE model parameters}

The parameters of the crystal plasticity model were identified from experimental data previously obtained at EDF research lab (Electricité de France ) [38]. The tests were performed on tensile specimens at five different temperatures $\left(\mathrm{RT},-60^{\circ} \mathrm{C},-90^{\circ} \mathrm{C},-120^{\circ} \mathrm{C},-150^{\circ} \mathrm{C}\right.$ ). The prescribed strain rate was set to $10^{-3} \mathrm{~s}^{-1}$ (Fig. 9). The strain rate sensitivity is low in the considered temperature range.

Cubic elasticity was used to describe the reversible part of the deformation. An isotropic distribution of grain orientations was chosen. Two slip families were introduced in the model in order to take into account the BCC structure of the material (family $<1 \overline{1} 0>\{111\}$ and family $<11 \overline{2}>\{111\}$ ). The viscosity parameter were chosen to limit the viscous effect. Self hardening and latent hardening due to interactions of slip systems were introduced by the matrices $h_{s r}^{b c c 110}$ and $h_{s r}^{b c c 112}$ [39]. Due to the lack of experimental information (monotonic tensile tests were used only), kinematic hardening was not considered here. Only isotropic hardening was considered; on the other hand, this hardening was supposed to be the same for each slip system family. We used a two step method for the identification of model parameters. This method consists of several optimization loops which use a uniform field model followed by FE computations performed on an aggregate containing 400 parent grains and 4700 bainitic packets mapped on a cubic mesh $(32 \times 32 \times 32$ elements $)$. The method is not presented here in detail for the sake of brevity. Interested readers can refer to [31]. The parameter set corresponding to $T=-120^{\circ} \mathrm{C}$ was used for the numerical study. It is reported in tables 2 and 3 (see for instance [32] for a detailed explanation of the various terms). 
6 Influence of crystallography and morphology of bainitic packets on the global and local strain-stress responses

\subsection{Problem presentation}

The influence of the microstructure on mechanical behaviour of bainitic steels was analysed by uniaxial tension simulation on different microstructures. Two types of grain geometry, equiaxed and bainitic, were taken into consideration. The equiaxed microstructure contained 120 grains described by Voronoï polyhedra and 99980 nodes in the FE mesh (average of 2954 Gauss points/grain). The bainitic microstructure was produced from the parent grains, by cutting each grain in about ten bainitic packets in average, using type $V$ algorithm, so that 1196 packets were generated in the new microstructure. A refined mesh containing 987151 nodes was used in this last case (average of 2986 Gauss points/grain), in order to preserve the same mesh density for both calculations. Note that an unstructured mesh was generated for the initial austenitic microstructure, so that the elements conform grain boundaries in this case. Bainitic packets were created by simply using a mapping technique, so that the relating microstructures introduced multiphase elements (packet boundaries going through elements). Four numerical tests were performed. For all of them, the material parameters were taken from Tab. 2. Their morphological and crystallographic characteristics are summarized in Fig. 10. Boundary conditions corresponding to a uniaxial tension test ( $5 \%$ of total deformation) have been applied in all cases (see 5.1 ).

- For the Grains ISO case, the 120 grain microstructure was computed by using a random distribution of the crystallographic orientations.

- The Grain NW aggregate uses the same mesh, with 120 domains, but now the crystal misorientations between adjacent domains were restricted to the 12 variants described by the Nishiyama-Wassermann relationships: this is like a large cubic grain with 120 bainitic packets. The purpose of this test is to 
1196 bainitic packets 987151 nodes 3570800 Gauss points 99980 nodes
354455 Gauss points
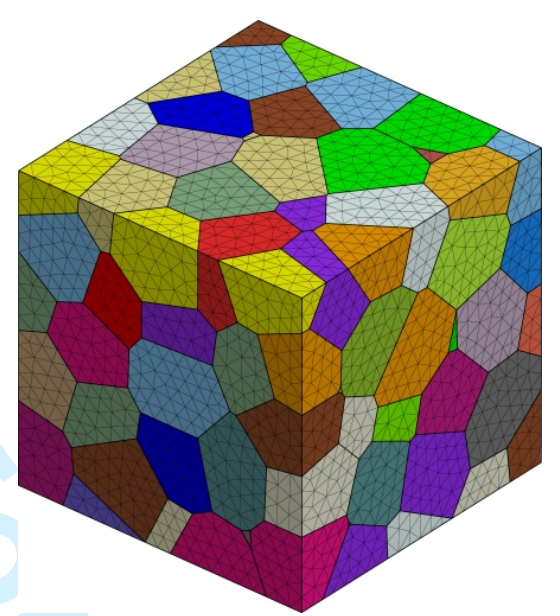

\begin{tabular}{l|c|c}
\hline $\begin{array}{l}\text { Random } \\
\text { orientations }\end{array}$ & $\begin{array}{c}\text { for grains } \\
\text { Grains ISO }\end{array}$ & $\begin{array}{c}\text { for all subgrains } \\
\text { Packets ISO }\end{array}$ \\
\hline \multirow{2}{*}{ NW relationships } & for grains & for subgrains in each grain \\
& Packets $I S O+N W$
\end{tabular}

Figure 10. The four computations made to check the influence of crystallography and morphology of bainitic packets on the global and local responses

quantify the effect of bainitic orientations on the mechanical response within the grain.

- For the Packets $I S O$ case, 1196 bainitic packets generated from the 120 grains representing the former austenitic phase were generated. Random crystallographic orientations were applied to each grain. This test will characterise the effect of the presence of the bainitic morphology (non equiaxed domains instead of equiaxed shapes) on the strain-stress responses by comparison with the Grains ISO test.

- A full model of the bainitic microstructure was considered in the Packets $I S O+N W$ case. This model contained the 1196 bainitic packets mentioned in the previous case. The crystal orientations of the phases were calculated by starting from the random distribution of orientations used in the first test, and then by applying NW relationships which connect the crystal orientation of the parent phase to bainitic packets orientation. These relationships were randomly chosen among the 12 variants. This model was then able to evaluate the joint effect of the morphology and the crystallography of the bainitic packets.

\subsection{Results and discussion}

Figure 11 shows the contour map of the von Mises equivalent stress at the surface of the different aggregates. An identical perspective and the same color scales are chosen for all images. The black lines represent grain boundaries of the former austenitic microstructure. In the case of the equiaxed grains (Fig. 11 (a) and (b)), the maximum stress is often localised near triple points and grains boundaries. Internal boundaries promote stress heterogeneity for the bainitic microstructure (Fig. 11 (c) and (d)). The map in Fig. 11 (b) is more heterogeneous than in Fig. 11 (a). It reveals a mixture of high stress concentration on badly misoriented grains and of grain boundaries that are not critical at all. The contrast between grains is larger than for the purely isotropic microstructure, because of the limited number of possible misorientations between the mesh subdomains. The non critical misorientations correspond either to $10^{\circ}$, or to perfectly oriented neighbors, when the same variant is present on both sides of the packet boundary. For a given morphology, the maximum value of the von Mises stress is $10 \%$ higher with NW grain boundaries than with ISO grain 


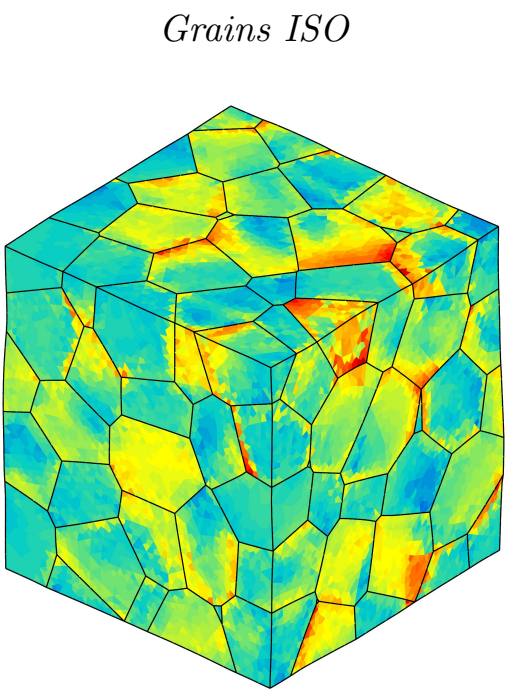

$\min : 417.64 \max : 1352.86$

(a)

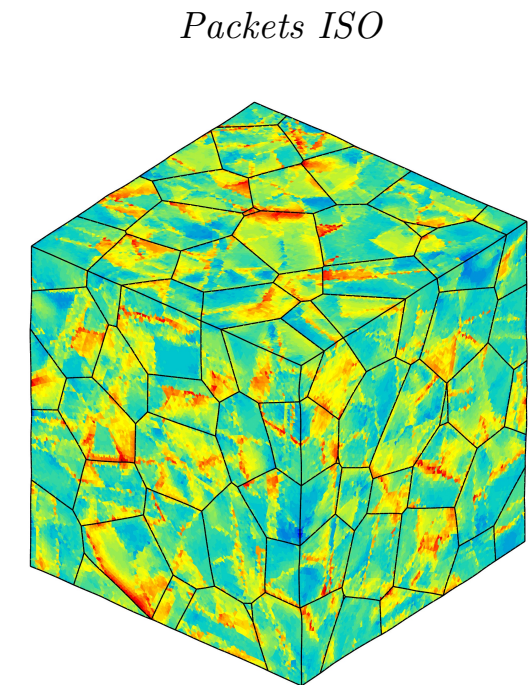

$\min : 293.80 \quad \max : 1538.00$

(c)

Figure 11. Von Mises equivalent stress distribution for various aggregates (MPa). (a) Grains ISO, (b) Grains NW, (c) Packets ISO, (d) Packets ISO+NW

boundaries. This has to be attributed to a real effect of the crystallography (and not to a mesh artifact), since the number of elements per domain is the same for both calculations. An effect of the morphology can also be observed, as illustrated in Fig. 11 (c). The maximum equivalent stress is now $1538 \mathrm{MPa}$, to be compared to $1353 \mathrm{MPa}$ in the equiaxed microstructure of the Grains ISO case. Stronger gradients are present in this case, since the minimum value of the equivalent stress is smaller for Packets ISO than for Grains ISO. The previous trends are confirmed in Fig. 11 (d), where a bainitic morphology superimposed to NW crystal orientations within grains yields higher maximum values and lower minimum values.

Analysis of the curves shown in Fig. 12 (mean value of the von Mises stress in each grain or each packet versus macroscopic strain) led to additional conclusions. The scatter observed on the stress-strain curves 


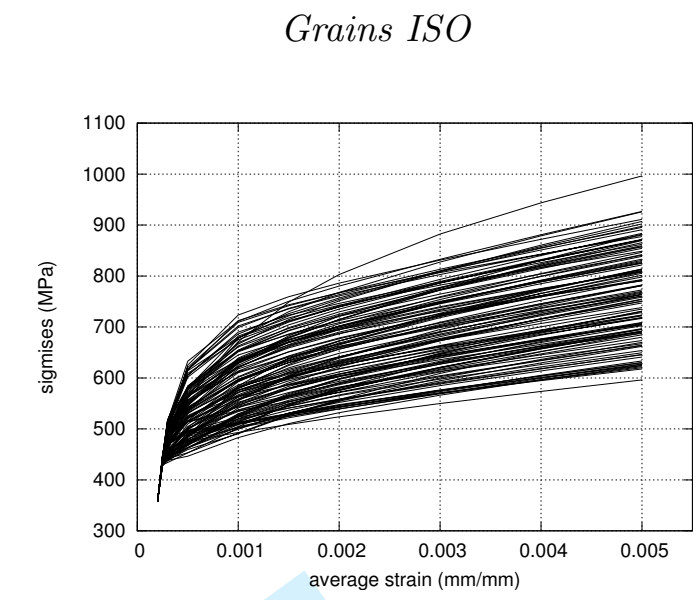

(a)

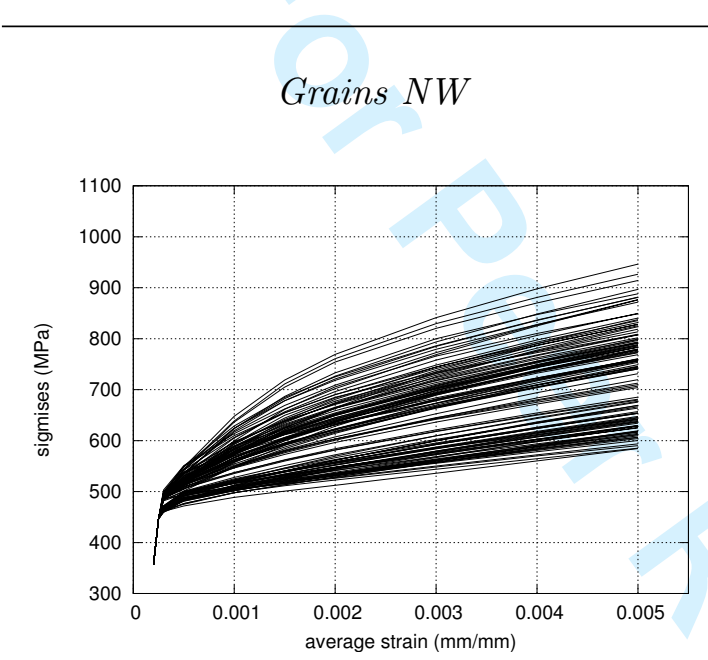

(b)
Packets ISO

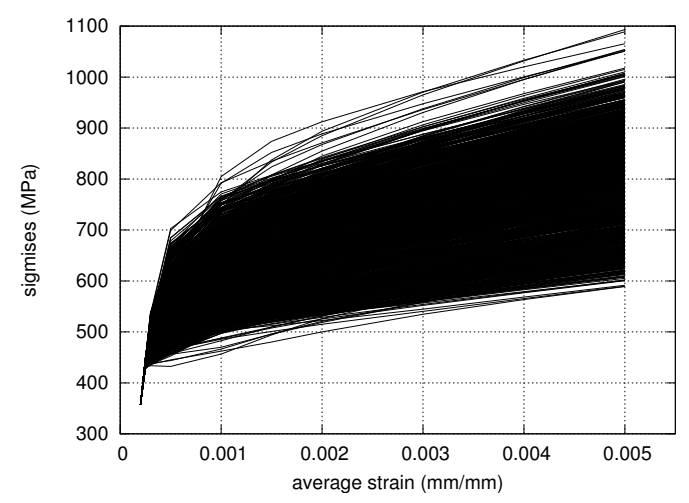

(c)

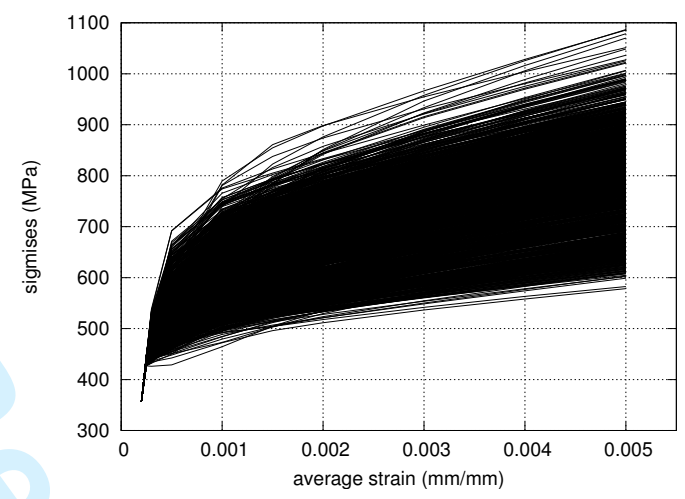

(d)

Figure 12. Mean value of the von Mises equivalent stress (by grain or by packet) function of the macroscopic strain

is larger for the bainitic microstructure than for the equiaxed one. The maximum average values in packets of bainite are $10 \%$ higher than in austenite. This confirms the previous results. On the other hand, the global behaviour in the Grains $N W$ case is much softer than the other three cases (Fig. 12 (b)). This is due to the reduced number of possible interactions, as discussed earlier. For the same reason, the plot made for Grains NW exhibits several categories of curves.

The curves showing the distribution of the von Mises equivalent stress corresponding to the end of the test (5\% average strain) are presented in Fig. 13. The two Packets curves and the Grains ISO curve present the same bimodal shape 13(a). On the contrary, a unique peak is observed for the Grains $N W$ computation. In the first three cases, there is a random choice of the misorientation: all the subdomains are randomly oriented for Grains ISO and Packets ISO. For Packets $I S O+N W$, even if the bainitic subdomains are not randomly oriented, the initial orientation of the parent grain introduces a random character, and it must be noted that (with ten packets in each initial grain) most of the packets have a common boundary with packets generated from an other former grain. It is therefore likely that the bimodal character of the curve is related to the random misorientation: following this assumption, the maximum at $600 \mathrm{MPa}$ would come from the bulk of the grain, and the maximum at $830 \mathrm{MPa}$ is produced by the region near grain/packet boundaries. Since there is only well defined misorientations in Grains $N W$, the second maximum vanishes. Due to the chosen boundary conditions, a spurious surface effect could be suspected. This is not the case: in fact, for the 120 grain microstructure, $64 \%$ of the grains touch on free surface, meanwhile for the 1196 packet microstructure, $34 \%$ packets touch on free surface: this produces a small increase of the lowest maximum for the Grains ISO case, but the effect remains small. 


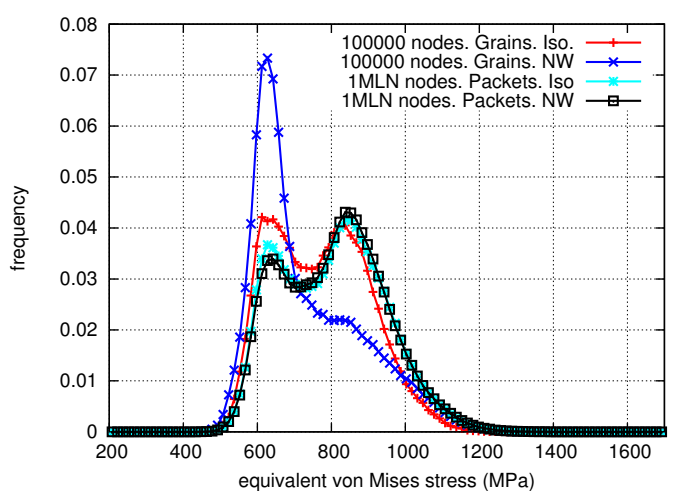

(a)

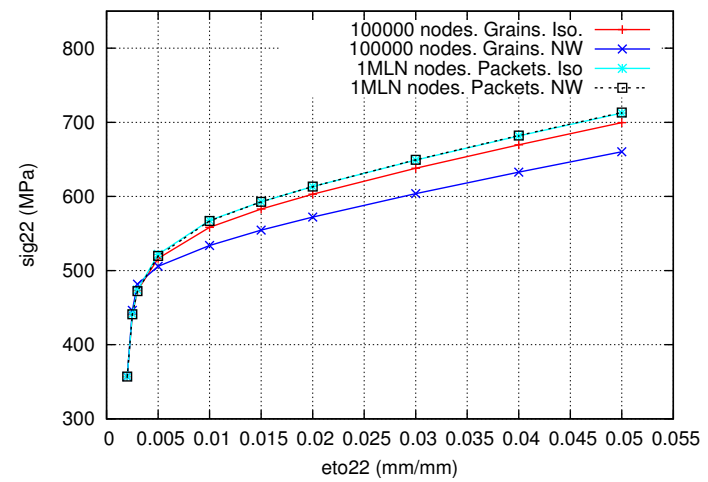

(b)

Figure 13. Von Mises equivalent stress distribution (5\% of deformation): (a) values at Gauss points, (b) Global stress-strain curve in direction of applied tension (22)

In agreement with the previous observations, the global curves (Fig. 13 (b)) are almost the same for the two Packets curves and the Grains ISO curve, with only a $10 \mathrm{MPa}$ difference between them. The very high maximum values reported in Fig.11 are then "erased" by the averaging operation. On the other hand, it is confirmed that Grains $N W$ curve remains below the other ones, due to the reduced number of interactions. Finally, it must be admitted that, when a large number of NW packets originating from the same parent grain are present, the local von Mises stress level decreases.

\section{Discussion of the influence of mesh type}

\subsection{Problem presentation}

In the previous sections, the computations have been made with unstructured meshes for the former equiaxed grains, but still with meshes using microstructure mapping and multiphase elements for the bainitic case (UM mesh type). For the present case, the bainitic mesh was generated with an alternative procedure which conforms packet boundaries (UU mesh type). The purpose of the computation was then to characterise the mechanical responses in this new framework. For the sake of comparison, two types of microstructures were considered, Grains and Packets, standing respectively for the equiaxed and the bainitic morphologies. In the Grains microstructure, 50 grains are described by Voronoï polyhedra. The manipulation of the bainitic sub-domains remains a fragile operation: the larger the number of grains, the more difficult the mesh generation. The number of 50 grains is a good compromise between the number of grains or sub-domains and the quality of the final mesh. In the present version of the code, this random crystallographic orientations were applied to each grain. In the Packets microstructure, the bainitic packets were generated from the initial equiaxed grains by using type $I V$ cutting rule. It contains 245 bainitic packets. NW relationships were used to generate the orientation of the bainitic packets in each grain. The main characteristics of the FE problem are presented in Fig. 14.

In order to make a relevant comparison between the results coming from the two computations, the mesh density was kept similar in each subdomain. The number of elements was 287154 for the Grains case (leading to an average number of 28715 Gauss points in each grain) and 1160933 for the Packets case (23692 Gauss points/grain).

\subsection{Results and discussion}

The main goal of this comparison was to control local and global responses of the aggregates with the new grain description. The second point was to understand how morphology and crystallography influence the shape of the curves characterising stress distribution. The results have to be compared to the previous analysis, namely Grains with Grains ISO (in both cases, a calculation with random orientations and an unstructured mesh of equiaxed grains), and Packets with Packets $I S O+N W$ (in both cases, a calculation 
\begin{tabular}{l|l} 
Equiaxed microstructure - Grains & Bainitic microstructure - Packets
\end{tabular}

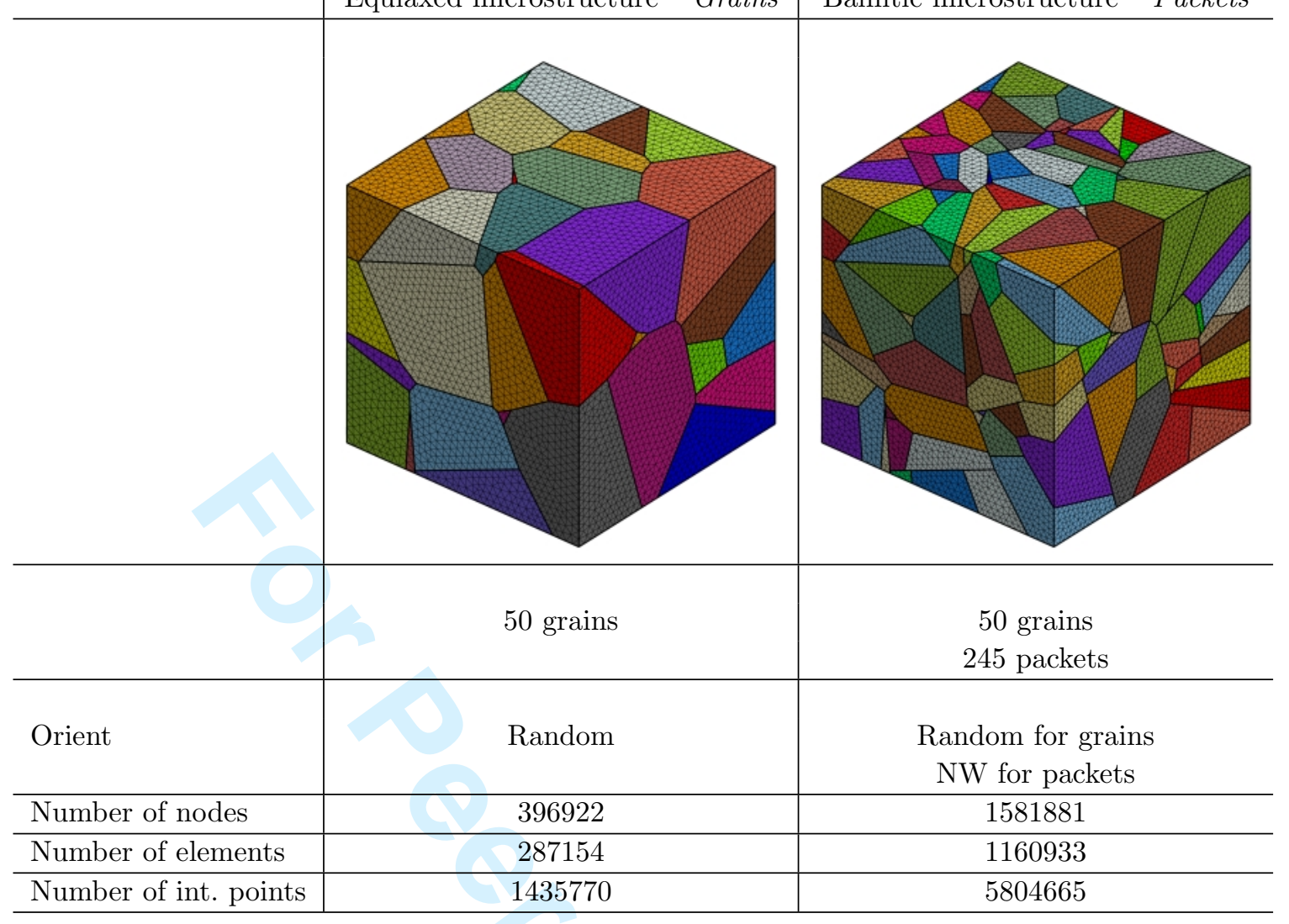

Figure 14. Influence of the microstructure description on the local and global responses. Problem presentation

with bainitic packets and the relevant orientations, but UU and UM meshes respectively). The maps of von Mises equivalent stress distribution obtained with the meshes shown in Fig.14 are presented in Fig. 15. Since the number of Gauss points representing each domain is now about ten times larger than in the previous section, a classical result [18] is recovered: if compared with the coarser mesh, the smallest stress value decreases and the largest stress value increases (compare Fig.11(a) and Fig.15(a)). UU algorithm provides smoother solutions if compared to those obtained with UM technique (Fig. 11 (d) and Fig. 15 (b)).

A quantitative comparison highlighting the mesh effect is made in Fig. 16. The von Mises stress distribution for the cases Grains ISO and Packets $I S O+N W$, previously shown in Fig. 11 (a), are plotted in Fig. 16(a) using a smaller stress range to have a better characterization of the peaks. The same plot is made for cases Grains and Packets with the new meshes in Fig. 16(c). The curves are also presented in $\log$-scales, respectively in Fig. 16(b) and Fig. 16(d): this allows us to analyse the global shape of the curves and to capture possible effects on both tails.

The main observation made from the equiaxed grain meshes is that the bimodal shape disappears for the new mesh (compare Grains to Grains ISO). This is due to the predominant effect of grains touching on free surface ( $82 \%$ among the 50 grains), leading to reduced constraints between the grains. On the other hand, surface effect is not so active for the Packets case, where only $53 \%$ of the packets are touching on surface: that is less than for Grains ISO. Nevertheless, the bimodal shape does not appear, and the curve is very close to the Grains result. The log-scale allows to check the similarity of the shapes even for the tails (Fig. 16(d)). The same plot for the older meshes (Fig. 16 (b)) exhibits a difference between the two computations. The results obtained with Packets $I S O+N W$ are shifted to the right (higher stresses) with respect to Grains ISO: the use of a mapping technique for bainitic packets generates large overstresses (more than $100 \mathrm{MPa}$ in the $10^{-4}-10^{-6}$ range), that should be considered as a numerical artifact. 


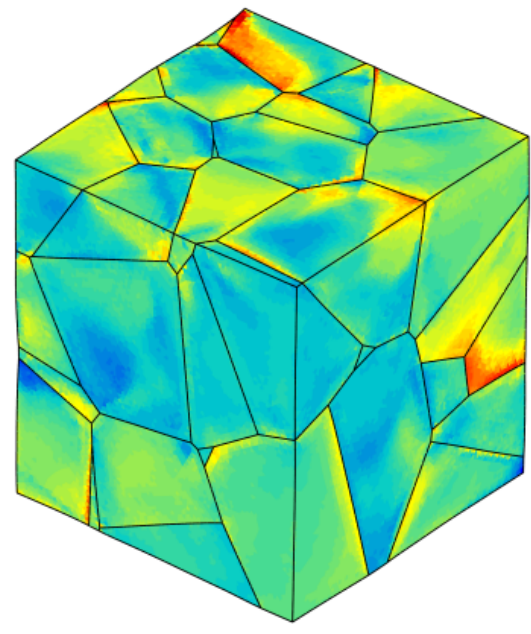

$\min : 248.46 \max : 1516.62$

(a)

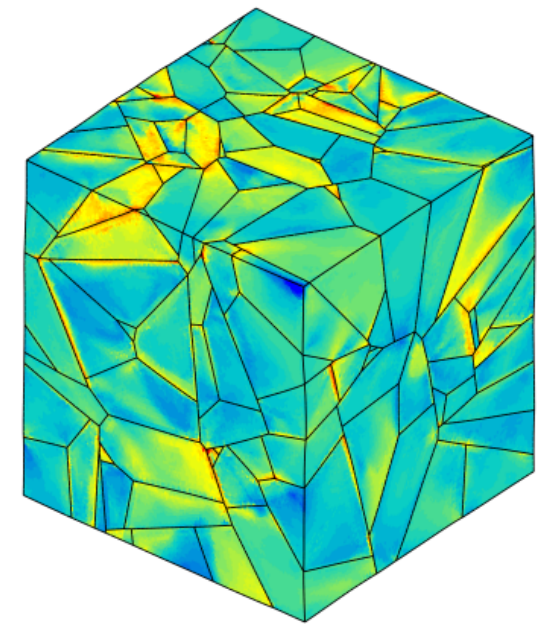

min: 72.49 max: 1535.95

(b)

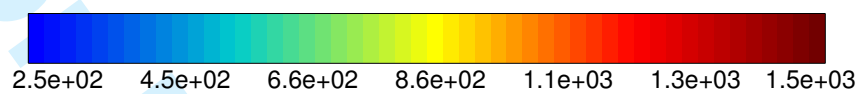

Figure 15. Equivalent von Mises stress distributions (MPa): (a) in equiaxed (Grains) microstructure; (b) in bainitic (Packets) microstructure (UU mesh) $\left(\epsilon_{\text {tot }}=4 \%\right)$

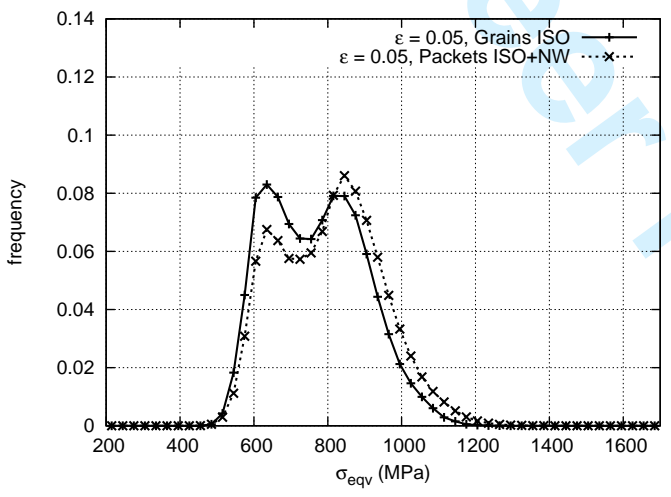

(a)

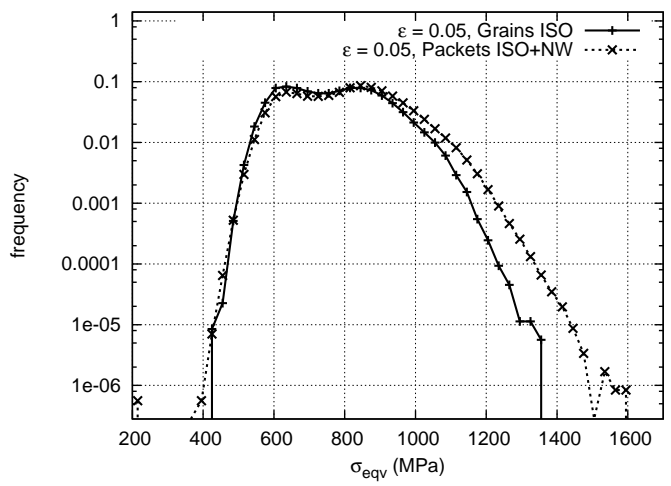

(b)

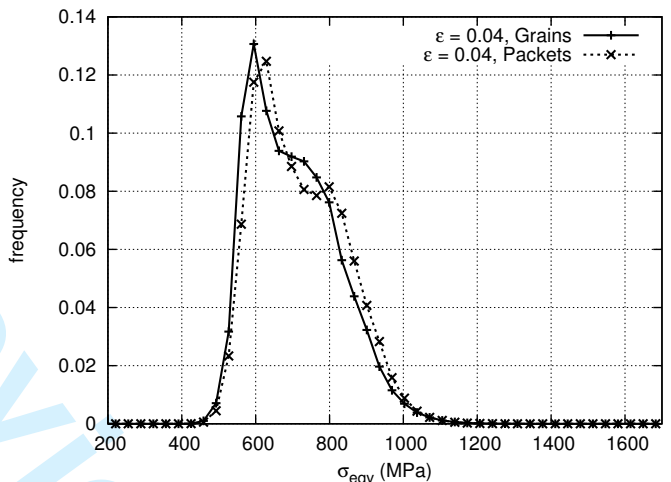

(c)

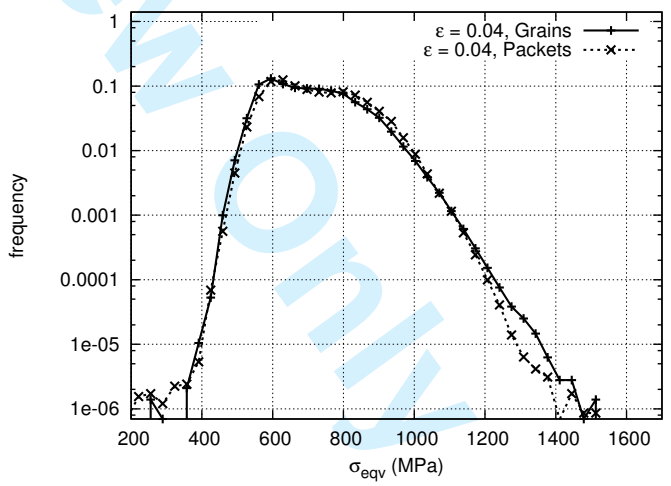

(d)

Figure 16. Equivalent von Mises stress distributions (MPa). (a) and (b) - results of computation using UM technique $\left(\epsilon_{t o t}=5 \%\right)$, (c) and $(\mathrm{d})$ - results of computation using UU technique $\left(\epsilon_{\text {tot }}=4 \%\right)$. Curves $(\mathrm{b})$ and $(\mathrm{d})$ are plotted in $l o g$-scale 


\section{Conclusion}

A new numerical method has been proposed to produce spatially controlled microstructures of bainitic steels. The influence of the morphology and of the local texture in the phases was investigated by means of finite element analysis of various configurations. The purpose of the study was to evaluate reliable local stress fields, to be used in a local micromechanical approach to predict brittle failure.

A bimodal shape of the von Mises stress distribution was exhibited on a few configurations. It is promoted by internal constraints, due to a large number of grains or packets, and/or to random misorientations. On the other hand, a distribution shape with one peak only is obtained either for free grains (any misorientations) or when the misorientations at grain boundaries are not random, as is the case for bainite packets inside a parent austenite grain.

One of the main questions addressed in this paper is the effect of a bainitic microstructure versus an equiaxed one. The geometry of packets (elongated subdomains) seems to have no intrinsic effect on the material behaviour. On the other hand, when a lot of boundary misorientations follow NW relationships (see Fig. 13 (b)) the resulting behaviour is softer than for randomly generated misorientations even at macroscopic scale.

The effect of mesh type and mesh size has also been studied. A spurious effect has been found with the UM type meshes, namely, when the bainitic packets are mapped on an unstructured mesh, so that the mesh does not conform the packet boundaries: this produces an increase in the local maximum stress, showing that multiphase elements are unable to provide a reliable prediction of local stresses. They must be avoided in such an application.

Finally, it must be mentioned that the number of elements must be large enough to capture the intergranular variations of the stress fields. Assuming that the number of grains is a few hundreds, a reasonable number of nodes must be in the $10^{6}-10^{7}$ range. Having in view the failure initiation model, a large number of elements is required anyway to characterise the shape of the tails of the curves, since, with $10^{6}$ Gauss points in the mesh, the frequency curve cannot have any point below $10^{-6}$.

\section{References}

[1] S. Carassou, S. Renevey, B. Marini, A. Pineau, ECF12 proceedings Sheffield, 2, 691, 1998.

[2] F.M. Beremin, A local criterion for cleavage fracture of nuclear pressure vessel steel, Metall. Trans., 14A (1983), pp. 2277-2287.

[3] Wallin K., Saario T., Törrönen K., Statistical model for carbide induced brittle fracture in steels, Metal Science, 18 (1984), pp. $13-16$.

[4] C. Eripret, D. Buisine, G. Rousselier, Seminar for promotion of local approach, Tempere April 28th - May 1st, 1992.

[5] B.Z. Margolin, A.G. Gulenko, V.A. Nikolaev, L.N. Ryadkov, New engineering method for prediction of the fracture toughness temperature dependence for RPV steels, Int. J. of Pres. Vessels and Piping, 80 (2003), pp. 817-829.

[6] C. Bouchet, B. Tanguy, J. Besson, S. Bugat, Prediction of the effects of neutron irradiation on the Charpy ductile to brittle transition curve of an A508 pressure vessel steel, Computational Materials Science, 32 (2005), pp. 294-300.

[7] M. Libert, Etudes expérimentale et numérique de l'effet des mécanismes de plasticité sur la rupture fragile par clivage dans les aciers faiblement allié, PhD thesis, Ecole Centrale de Paris (2007).

[8] J.J. Gilman, Fracture, B.L. Averbach, G.T. Hahn et al Editors, New York, 1959, pp. 193-224.

[9] A.T. Price, H.A. Holl, A.P. Greenough, The surface energy and self diffusion coefficient of solid iron above $1350 \mathrm{C}$, Acta Metall., 12 (1964), pp. 49-58.

[10] P. Bowen, S.G. Druce, J.F. Knott, Effects of microstructure on cleavage fracture in pressure vessel steel, Acta Metall., 34 (1986), pp. 1121-1131.

[11] S.G. Roberts, Proc. of "Multiscale Phenomena in Plasticity", 8-19 September, Ouranopolis, Greece, 1999.

[12] D. Lidbury, S. Bugat, O. Diard, E. Keim, B. Marini, H.-W. Viehrig, K. Wallin, PERFECT (Prediction of Irradiation Damage Effects in Reactor Components): Overview of RPV Mechanics Sub-Project, Proceedings of ASME PVP 2005, Denver, Colorado, July 17-21, 2005

[13] G. Cailletaud, S. Forest, D. Jeulin, F. Feyel, I. Galliet, V. Mounoury, S. Quilici, Some elements of microstructural mechanics, Computational Materials Science, 27 (2003), pp. 351-374.

[14] S.R. Kalidindi, C.A. Bronkhorst, L. Anand, Crystallographic texture evolution in bulk deformation processing of FCC metals, J. Mech. Phys. Sol., 40 (1992), pp. 536-569.

[15] C. Miehe, J. Schröder, J. Schotte, Computational homogenization analysis in finite plasticity. Simulation of texture development in polycrystalline materials, Comp. Meth. Appl. Mech. Engng, 171 (1999), pp. 387-418.

[16] D.P. Mika, P.R. Dawson, Effects of grain interaction on deformation in polycrystals, Material Science and Engineering, 257 (1998), pp. 62-76.

[17] N. Lippmann, Th. Steinkopff, S. Schmauder, P. Gumbsch, 3D-finite-element-modelling of microstructures with the method of multiphase elements, Computational Materials Science, 9 (1997), pp. 28-35.

[18] F. Barbe, L. Decker, D. Jeulin, G. Cailletaud, Intergranular and intragranular behavior of polycrystalline aggregates. Part I: FE model, Int. J. Plast., 17 (4) (2001), pp. 513-536.

[19] A. Musienko, A. Tatschl, K. Schmidegg, O. Kolednik, R. Pippan, G. Cailletaud, Three-dimensional finite element simulation of a polycrystalline copper specimen, Acta Materialia, 55 (2007), pp. 4121-4136. 
N. Osipov et al.

[20] E. Héripré, M. Dexet, J. Crépin, L. Gélébart, A. Roos, M. Bornert, D. Caldemaison, Coupling between experimental measurements and polycrystal finite element calculations for micromechanical study of metallic materials, Int. J. Plast., 23 (2007), pp. 1512-1539.

[21] D. Raabe, M. Sachtleber, Z. Zhao, F. Roters, S. Zaefferer, Micromechanical and macromechanical effects in grain scale polycrystal plasticity experimentation and simulation, Acta Metall., 49 (1981), pp. 3433-3441.

[22] F. Gourgues, H.M. Flower, T.C. Lindley, Electron backscattering diffraction study of acicular ferrite, bainite and martensite steel microstructures, Materials Science and Technology, 16, 1 (2000), pp. 26-40.

[23] M. Hillert, Viewpoint Set on: Bainite, Scr. Mater. 47 (2002), pp. 137-212 (special issue on bainite).

[24] G.V. Smith, R.F. Mehl: Lattice Relations in Decompositions of Austenite to Pearlite, Bainite, and Martensite. Trans. Metall. Soc. AIME, 150 (1942), pp. 211-226.

[25] Y. Ohmori, Y.-C. Jung, K. Nakai, H. Shioiri : Bainite transformation and the diffusional migration of bainite/austenite broad interfaces in Fe-9\%Ni-C alloys, Acta Mater., 49 (2001), pp. 3149-3162.

[26] H.-K.-D.-H. Bhadeshia, Bainite in Steels (Cambridge University Press, 2001).

[27] J.-P. Mathieu, Analyse et modélisation micromécanique du comportement et de la rupture fragile de l'acier 16MND5 : prise en compte de hétrogénéités microstructurales, PhD thesis, ENSAM de Metz (2006).

[28] G. V. Kurdjumov and G. Z. Sachs, Zeitschrift für Physik, 64, 325 (1930).

[29] Z. Nishiyama, Sci. Repts, (Tohoku Imp. Univ., Japan, 1934).

[30] G. Wassermann, Technical report (Mitt. K.-Wilh. Inst. Eisenforsh, 1935).

[31] N. Osipov, Generation and numerical study of bainitic microstructures, intragranular local approach to fracture, PhD thesis, Mines Paristech, France (2007).

[32] P. Franciosi, The Concepts of Latent Hardening and Strain Hardening in Metallic Single Crystals, Acta Metall., 33 (1985), pp. $1601-1612$

[33] A. Lambert-Perlade, A.-F. Gourgues and A. Pineau, Austenite to bainite phase transformation in the heat affected zone of a high strength low alloy steel, Acta Mater. 52, pp. 2337-2348 (2004).

[34] J. K. McKenzie, The distribution of rotation axes in a random aggregate of cubic crystals, Acta Metall. 12 (1964), pp. $223-225$.

[35] C. Fahrat and F.-X. Roux, Implicit Parallel Processing in Structural Mechanics, Computational Mechanics Advances, 2 (1994), pp. $1-124$.

[36] L. Méric and G. Cailletaud, Single Crystal Modelling for Structural Calculations. Part 2: Finite Element Implementation. J. Eng. Mater. Technol. 113, (1991) pp. 171-182.

[37] F. Barbe, S. Forest and G. Cailletaud, Intergranular and intragranular behavior of polycrystalline aggregates. Part II: Results, Int. J. Plast., 17 (2001), pp. 537-566.

[38] S. Renevey, Approches globale et locale de la rupture dans le domaine de transition fragile-ductile d'un acier faiblement allié, PhD thesis, University of Paris XI Orsay (1998).

[39] U.F. Kocks and T.J. Brown, Latent Hardening in Aluminium, Acta Metall. 14 (1966), pp. 87-98. 